\title{
BMJ Open National survey to estimate sodium and potassium intake and knowledge attitudes and behaviours towards salt consumption of adults in the Sultanate of Oman
}

Adhra Al-Mawali, ${ }^{1,2}$ Lanfranco D'Elia, ${ }^{3,4}$ Sathish Kumar Jayapal, ${ }^{1}$ Magdi Morsi, ${ }^{1}$ Waleed Nasser Al-Shekaili, ${ }^{1}$ Avinash D Pinto, ${ }^{1}$ Hilal Al-Kharusi, ${ }^{1}$ Zainab Al-Balushi, ${ }^{1}$ John Idikula, ${ }^{1}$ Ayaman Al-Harrasi, ${ }^{1}$ Francesco P Cappuccio (i) ${ }^{3,5,6}$

To cite: Al-Mawali A, D'Elia L, Jayapal SK, et al. National survey to estimate sodium and potassium intake and knowledge attitudes and behaviours towards salt consumption of adults in the Sultanate of Oman. BMJ Open 2020;10:e037012. doi:10.1136/ bmjopen-2020-037012

- Prepublication history and additional material for this paper is available online. To view these files, please visit the journal online (http://dx.doi.org/10. 1136/bmjopen-2020-037012).

Received 16 January 2020 Revised 28 July 2020 Accepted 30 August 2020
D) Check for updates

(c) Author(s) (or their employer(s)) 2020. Re-use permitted under CC BY. Published by BMJ.

For numbered affiliations see end of article.

\section{Correspondence to}

Professor Francesco P

Cappuccio;

f.p.cappuccio@warwick.ac.uk

\section{ABSTRACT}

Objectives To estimate population sodium and potassium intakes and explore knowledge, attitudes and behaviour (KAB) towards the use of salt in adults in the Sultanate of Oman.

Design National cross-sectional population-based survey. Setting Proportional random samples, representative of Omani adults (18 years or older), were obtained from all governorates of the Sultanate of Oman.

Participants Five hundred and sixty-nine (193 men, 376 women; 18 years or older) were included in the analysis (response rate 57\%). Mean age was 39.4 years (SD 13.1). Participants attended a screening including demographic, anthropometric and physical measurements.

Primary and secondary outcome measures We assessed dietary sodium, potassium and creatinine by 24hour urinary sodium (UNa), potassium (UK) and creatinine (UCr) excretions. We collected KAB by a questionnaire on an electronic tablet.

Results Mean UNa was $144.3(78.8) \mathrm{mmol} / \mathrm{day}$, equivalent to $9.0 \mathrm{~g}$ of salt/day and potassium excretion 52.6 (32.6) $\mathrm{mmol} /$ day, equivalent to $2.36 \mathrm{~g} /$ day, after adjusting for non-urinary losses. Men ate significantly more sodium and potassium than women. Only $22 \%$ of the sample had a salt intake below the WHO recommended target of $5 \mathrm{~g} /$ day and less than $10 \%$ met WHO targets for potassium excretion (>90 mmol/day). While $89.1 \%$ of those interviewed knew that consuming too much salt could cause serious health problems and only $6.9 \%$ felt they were using too much added salt, one in two participants used always or often salt, salty seasonings or salty sauces in cooking or when preparing food at home.

Conclusions In the Sultanate of Oman, salt consumption is higher and potassium consumption lower than recommended by WHO, both in men and in women. The present data provide, for the first time, evidence to support a national programme of population salt reduction to prevent the increasing burden of cardiovascular disease in the area.

\section{Strengths and limitations of this study}

- National survey of Omani men and women using 24hour urine collections.

- Adoption of quality control process to minimise the use of incomplete urine collections.

- Overall response rate was $57 \%$, comparable with other similar population surveys.

- Non-responders did not differ in their baseline characteristics from responders.

- We cannot rule out the risk of selection bias.

\section{INTRODUCTION}

Non-communicable diseases (NCDs) are the leading, yet preventable, causes of death worldwide. $^{1}$ The reduction of its burden is now a global health priority of the $\mathrm{UN},{ }^{2}$ endorsed by the WHO Action Plan that has identified a set of cost-effective policy options ('best buys'), of which reduction in population salt consumption is one. ${ }^{3}$

In the Sultanate of Oman, NCDs are among the leading causes of death, accounting for $72 \%$ of all deaths. ${ }^{4}$ Cardiovascular disease (CVD) represents an increasingly common cause of population morbidity and mortality, accounting for $36 \%$ of all deaths. ${ }^{4}$ It represents a major public health challenge undermining socioeconomic development. ${ }^{5}$

High blood pressure (BP) and unhealthy diets are the leading risk factors for CVD in the world. ${ }^{1}$ Raised BP is a determinant of the CVD risk in the Sultanate of Oman, where the prevalence of raised BP in people aged 18 years or older is $33 \%$, higher in men $(39 \%)$ than in women $(27 \%) .{ }^{56}$

High salt (ie, sodium chloride, $1 \mathrm{~g}=17.1 \mathrm{mmol}$ of sodium) consumption is an important determinant of high BP. A high salt 
intake is associated with raised BP that leads to increased risk of vascular diseases. ${ }^{7-10}$ In addition, high salt intake is related to adverse health effects independent of its effects on BP. ${ }^{11-13} \mathrm{~A}$ moderate reduction in salt consumption reduces $\mathrm{BP}^{78}$ and it can improve the health outcomes and indirectly reduce the overall mortality through beneficial effect on the BP. ${ }^{910}$

The WHO recommends that adults should consume no more than $5 \mathrm{~g}$ of salt daily. ${ }^{14}$ However, mean daily intakes of salt in most of the countries in the world exceed this recommendation. ${ }^{1516}$ While there is no definitive estimate of population dietary salt intake in the Sultanate of Oman, average consumption could be high, similar to some countries in the subregion. ${ }^{17} 18$ In the Sultanate of Oman, it is a common habit to add salt and salty condiments to food at the table and while cooking. Also, the habit of eating out is increasing (especially in urban areas), which leads to an increased salt intake, since restaurants tend to use higher amounts of salt to render food tastier. Our study was designed to support the salt reduction strategy of the Eastern Mediterranean region (EMRO), including the Sultanate of Oman, in which monitoring population salt consumption is one of the three pillars. ${ }^{19}$ Current national initiatives include establishment of a multisectoral national committee, legislation on salt reduction, development of salt content benchmarks, dietary guidelines. ${ }^{18}$ The 'Health Vision 2050' for the Sultanate of Oman was also developed as a roadmap by analysing extensively the status of the Omani health system, the morbidity and mortality in the population, the challenges facing the health system, the expected future developments and changes in the population including macrosocial and macroeconomic changes in order to augment the performance of the health system.

In contrast to sodium, epidemiological and intervention studies suggest beneficial effects of dietary potassium on BP and cardiovascular health. ${ }^{20-22}$ The Sultanate of Oman lacks data on actual potassium consumption. The WHO currently recommends that adults should consume not less than $90 \mathrm{mmol}$ of potassium daily. ${ }^{23}$ Hence, we need reliable data on sodium and potassium intake in the Sultanate of Oman.

The primary aim of the present study was to establish current baseline average consumption of sodium and potassium by 24-hour urine collection, in a national random sample of Omani men and women. The study also aimed to explore knowledge, attitudes and behaviour (KAB) towards dietary salt.

\section{MATERIAL AND METHODS}

\section{Participants and recruitment}

We nested the salt survey within the main Oman NCD survey of 6833 households (online supplemental material 1 , text S1). We recruited only one member per household. We designed the salt survey to collect 24-hour urinary samples from a subgroup of at least 90 participants from each governorate (region). The survey included only

\begin{tabular}{lcr}
\hline $\begin{array}{l}\text { Table } 1 \\
\text { Oman }\end{array}$ & Geographical sampling from the Sultanate of \\
\hline Governorate & Valid 24-hour urine collections & \multicolumn{1}{c}{$\%$} \\
\hline Muscat & 67 & 11.8 \\
\hline Dhofar & 79 & 13.9 \\
\hline Al-Dakhlia & 45 & 7.9 \\
\hline North Sharqiah & 36 & 6.3 \\
\hline South Sharqiah & 45 & 7.9 \\
\hline North Batina & 81 & 14.2 \\
\hline South Batina & 53 & 9.3 \\
\hline Al-Dhahirah & 46 & 8.1 \\
\hline Al Buraymi & 84 & 14.8 \\
\hline Musandam & 9 & 1.6 \\
\hline Al-Wasta & 24 & 4.2 \\
\hline Total & 569 & 100.0 \\
\hline
\end{tabular}

Omani citizens. We included a total of 999 randomly selected Omani men and women. They were all aged 18 years or older. They comprised residents of all governorates of the Sultanate of Oman (table 1). The sample was representative of the national sample for its general characteristics (see online supplemental table 1).

From the sampling frame and according to the EMRO-WHO Protocol, ${ }^{24}$ we excluded the following groups: people unable to provide informed consent, those with known history of heart or kidney failure, stroke, liver disease, those who recently began therapy with diuretics (less than 2 weeks), pregnant women, any other conditions that would make 24-hour urine collection difficult. To detect approximately $1 \mathrm{~g}$ reduction in salt intake over time using 24-hour urinary sodium excretion (difference $\sim 20 \mathrm{mmol} / 24$ hours), with an SD of $75 \mathrm{mmol} /$ day (alpha $=0.05$, power $=0.80$ ), a minimum sample of 120 individuals per stratum is recommended. ${ }^{24}$ Thus, we estimated a minimum recommended sample size of 240 per age and sex groups and adjusted for an anticipated nonresponse rate of $50 \% .{ }^{24}$ We stratified the population in groups by sex (men and women). Therefore, 480 individuals were originally needed to be selected (total $n=120 \times 2$ groups $/ 0.5$ attrition $=480$ ).

The survey took place between December 2017 and May 2018. From the 999 individuals interviewed in the sampling frame, 569 of them $(57.0 \%)$ provided suitable data for inclusion in the survey analysis. The general characteristics of the included participants did not differ substantially from those of the excluded participants (see online supplemental table 2). Originally, $262(26.0 \%)$ did not provide complete urine collections (either declaring missing more than one void or providing collections $<23$ hour or above 25 hours), 87 (8.7\%) had missing data, $48(4.8 \%)$ provided urine collections with volume less than $500 \mathrm{~mL}$ (conventionally taken as not plausible) and $24(2.4 \%)$ had urinary creatinine excretion outside two 
Included

Excluded

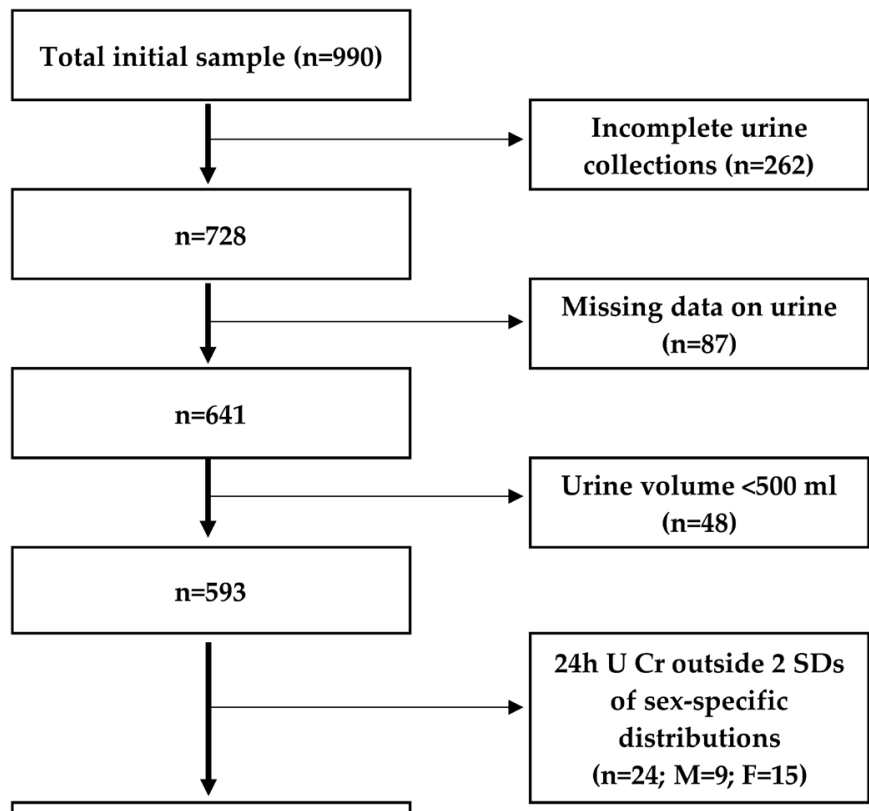

Figure 1 Stepwise procedure for the selection of valid participants according to protocol adherence, quality control and completeness of 24-hour urine collections.

SDs of the sex-specific distribution of urinary creatinine in the sample (figure 1).

\section{Ethical considerations}

We carried out the survey in accordance with the Declaration of Helsinki and Good Clinical Practice. ${ }^{25}$

\section{Patient and public involvement}

No patient involved.

\section{Data collection}

We performed the examination in a quiet and comfortable room, with the participants who did not smoke, exercise, eat and consume caffeine before attending and had been instructed to present with a full bladder $30 \mathrm{~min}$ before measurements to reduce the risk of underestimating the urine collection. We carried out the survey in three steps: (a) questionnaire survey, (b) physical measurements and (c) 24-hour urine collections.

We based the questionnaire on the Core and Expanded version of the WHO STEPS Instrument for Chronic Disease Risk Factor Surveillance (V.3.0 ${ }^{26}$ and countryspecific requirements. It contained 11 core, 1 optional and 4 country-specific modules that included a total of 420 questions, to determine sociodemographic characteristics of participants, key behavioural risk factors (tobacco use, harmful alcohol consumption, diet with frequency of fruit and vegetable consumption, high dietary salt consumption, oil and fat use, physical inactivity), knowledge attitudes and behaviour on dietary salt, given lifestyle advises and additional health-related information not presented here. KABs towards the consumption of salt were assessed by asking participants about the frequency, quantity and type of salt used in the household as well as their cooking habits and their attitudes and perceptions towards dietary salt intake. Processed food was defined, per WHO STEPS protocol, as foods altered from their natural state, such as packaged salty snacks, canned salty food, cheese and processed meat along with country-specific pictorial show cards.

We measured anthropometric indices, BP and heart rate in all participants. Height was in centimetre and body weight in kilogram using a standardised and calibrated SECA813 digital floor scales and 213 portable stadiometers, respectively. Body mass index (BMI) was calculated as weight $(\mathrm{kg})$ divided by height squared $\left(\mathrm{m}^{2}\right)$. Waist and hip circumferences were measured by a non-stretch SECA201 measuring tape to the nearest millimetre. ${ }^{24}$ We took systolic and diastolic BP and heart rate measurements three times in the right arm on a sitting position, using an appropriate cuff and a validated digital device (OMRON M3). We ignored the first measurement and used the mean of second and third measurements for analysis. We took measurements after the participant had rested for $15 \mathrm{~min}$ and each with 3 min of rest between the measurements (maximum deviation of cuff pressure measurement $\pm 3 \mathrm{~mm} \mathrm{Hg}$ and of pulse rate display $\pm 5 \%$ ). Hypertension is defined as systolic and/or diastolic BP $\geq 140 / 90 \mathrm{~mm} \mathrm{Hg}$ or regular antihypertensive treatment. ${ }^{27}$ We obtained a single 24-hour urine collection from the participants. We gave each participant a leaflet with explanations along with the necessary equipment and a record sheet on which they noted the start and the finish times of their urine collection, any missed urine aliquots and any medication taken during the collection. We instructed the participants carefully on urine collection methodology. ${ }^{24}$ In an effort to minimise bias, we also requested participants not to change their diet before or during the day of the urine collection. They discarded the first void on waking on the day of collection. Participants then filled the 24-hour urine container over the 24-hour period. On the following day, the field team members visited the household, measured total volume, mixed it thoroughly and obtained a urine sample, which was kept in a cool box for transport to the respective laboratory. On arrival at the laboratory, we either carried out sodium, potassium and creatinine determinations immediately or stored samples in the fridge until the determination (as soon as possible). Sodium and potassium concentration in the urine samples were determined using an ion-selective electrode with an Abott C8000 \& Roche Cobas 6000 and expressed in $\mathrm{mmol} / \mathrm{L}{ }^{28}$ Creatinine concentration was determined through either the kinetic (Abbott C8000) or enzymatic (Roche Cobas 6000) method and expressed in $\mathrm{mg} / \mathrm{dL}{ }^{29}$ These determinations were carried out in one reference laboratory in each of the 11 governorates, except for two regions (Dhofar and Musandam) which 
had two receiving reference laboratories each. All laboratories underwent joint quality control.

\section{Statistical analysis}

We performed all statistical analyses using the SPSS software, V.20 (SPSS). We used t-test for unpaired samples to assess differences between group means and Pearson $\chi^{2}$ test to test the association between categorical variables. To convert urinary output into dietary intake, we first converted the urinary excretion of sodium (UNa) or potassium (UK) values ( $\mathrm{mmoL} /$ day) into $\mathrm{mg} /$ day (for sodium $1 \mathrm{mmol}=23 \mathrm{mg}$ of sodium, for potassium $1 \mathrm{mmol}=39 \mathrm{mg}$ ). We then multiplied the sodium value by 2.542 to convert dietary sodium $(\mathrm{Na})$ intake into salt $(\mathrm{NaCl})$ intake. We finally multiplied sodium values by 1.05 (assuming that approximately $95 \%$ of sodium ingested is excreted) ${ }^{30} \mathrm{We}$ calculated potassium dietary intake assuming that $85 \%$ of the potassium ingested is excreted in the urine. ${ }^{31}$ The results were reported as mean (SD), median (IQ range) or as percentages, as appropriate. We considered twosided p below 0.05 as statistically significant.

\section{RESULTS}

The final population sample included 569 participants between 18 and 69 years old $(n=193$ or $34 \%$ men and $\mathrm{n}=376$ or $66 \%$ women), recruited nationally.

\section{Characteristics of the participants}

Table 2 shows the characteristics of the participants. There was no statistically significant difference in the mean age and in BMI between men and women, however, men had significantly higher BP and slower heart rate than women had. The prevalence of hypertension was on average of $27.4 \%$, significantly higher in men than in women $(38.5 \%$ vs $21.7 \%, \mathrm{p}<0.001)$.

Daily urinary excretions of volume, sodium, potassium and creatinine and salt and potassium intake

Average urinary volume excretion was $1354 \mathrm{~mL}$ /day, being higher in men than women (table 3). Average urinary creatinine excretion was $1.33 \mathrm{~g} /$ day, being again higher in men than women (table 3 ). Mean urinary sodium was 144.3 (SD 78.8) $\mathrm{mmol} / 24$ hours, equivalent to a mean consumption of 9.0 (4.9) g of salt per day (table 3). Men excreted more sodium than women did (mean difference $15.0 \mathrm{mmol} / 24$ hours, $\mathrm{p}<0.05$ ), equivalent to $\sim 1.0 \mathrm{~g}$ of higher salt consumption than women did. Only $22 \%$ of the participants met the levels of salt intake of $5 \mathrm{~g}$ or less recommended by the WHO, with no difference between sexes. Mean urinary potassium was 52.6 (32.6) $\mathrm{mmol} / 24$ hours, equivalent to a mean consumption of 2.36 (1.46) $\mathrm{g}$ of potassium per day (table 3 ).

Men excreted significantly more potassium than women; $9.1 \%$ of participants met the levels of potassium intake of $90 \mathrm{mmol} /$ day or more recommended by the WHO.

The sex difference in total daily salt and potassium intakes is almost entirely due to the fact that men eat more food than women, as they are taller and heavier, despite having comparable BMI. This is a consistent finding across populations in different countries and from different continents.

KABs towards salt intake and other eating patterns.

KABs towards the consumption of salt are presented in table 4 . A total of $28.1 \%$ of respondents mentioned that

\begin{tabular}{llll}
\hline Table 2 Characteristics of the participants & & & \\
\hline Variable & All $(\mathbf{n}=\mathbf{5 6 9})$ & Men $(\mathbf{n}=\mathbf{1 9 3})$ & Women $(\mathbf{n}=\mathbf{3 7 6})$ \\
\hline Age $($ years $)$ & $39.4(13.1)$ & $38.7(14.3)$ & $39.8(12.5)$ \\
Height $(\mathrm{cm}) \dagger$ & $159.4(11.2)$ & $167.9(9.7)$ & $154.9(9.2) \ddagger$ \\
Weight $(\mathrm{kg}) \dagger$ & $74.9(21.5)$ & $81.4(22.5)$ & $71.4(20.1) \ddagger$ \\
Body mass index $\left(\mathrm{kg} / \mathrm{m}^{2}\right) \dagger$ & $29.3(7.2)$ & $28.9(7.6)$ & $29.5(7.0)$ \\
Waist circumference $(\mathrm{cm}) \dagger$ & $93.8(15.7)$ & $95.0(15.7)$ & $93.2(15.7)$ \\
Hip circumference $(\mathrm{cm}) \dagger$ & $104.5(15.0)$ & $102.6(13.7)$ & $105.5(15.6) \S$ \\
Systolic blood pressure $(\mathrm{mm} \mathrm{Hg})^{\star}$ & $125.9(18.2)$ & $134.0(17.0)$ & $121.7(17.3) \ddagger$ \\
Diastolic blood pressure $(\mathrm{mm} \mathrm{Hg})^{\star}$ & $80.9(10.7)$ & $83.4(11.5)$ & $79.7(10.1) \ddagger$ \\
Pulse rate $(\mathrm{b} /$ min)* & $79.8(10.5)$ & $78.5(11.8)$ & $80.4(9.8) \S$ \\
Hypertension N $(\%)^{\star}$ & $175(30.8)$ & $77(39.9)$ & $98(26.1) \ddagger$ \\
On antihypertensives N $(\%)^{\star}$ & $50(28.6)$ & $15(19.5)$ & $35(35.7) \S$ \\
\hline
\end{tabular}

Results are mean (SD) or $\mathrm{N}(\%)$.

Hypertension: Systolic Blood Pressure / Diastolic Blood Pressure $>140 / 90 \mathrm{~mm} \mathrm{Hg}$ or on current therapy for high blood pressure.

${ }^{*} 3$ missing values $(1 \mathrm{~m}, 2 \mathrm{w})(0.5 \%)$.

†18 missing values $(1 \mathrm{~m}, 17 \mathrm{w})(4 \%)$.

$\neq \mathrm{p}<0.01$.

$\S \mathrm{p}<0.05$ when compared with men. 
Table 3 Daily urinary excretions of volume, sodium, potassium and creatinine, estimates of salt and potassium intake and proportion of participants meeting WHO recommended targets for salt and potassium consumption.

\begin{tabular}{|c|c|c|c|}
\hline Variable & All $(n=569)$ & Men $(n=193)$ & Women $(n=376)$ \\
\hline \multirow[t]{2}{*}{ Volume (mL/24 hours) } & $1354(725)$ & $1392(712)$ & $1335(731)^{*}$ \\
\hline & $1129(855-1618)$ & $1150(900-1721)$ & $1122(827-1593)$ \\
\hline \multirow[t]{2}{*}{ Sodium (mmol/24 hours) } & $144.3(78.8)$ & $154.2(87.4)$ & $139.2(73.6)^{\star}$ \\
\hline & $129.6(85.7-187.4)$ & $135.4(87.1-204.8)$ & $126.8(83.9-179.4)$ \\
\hline \multirow[t]{2}{*}{ Potassium (mmol/24 hours) } & $52.6(32.6)$ & $56.4(32.4)$ & $50.6(32.5)^{\star}$ \\
\hline & $46.4(31.4-64.9)$ & $50.9(33.8-73.2)$ & $44.7(30.2-61.6)$ \\
\hline \multirow[t]{2}{*}{ Sodium-to-potassium ratio } & $3.3(3.4)$ & $3.5(4.2)$ & $3.2(2.8)$ \\
\hline & $2.8(2.0-3.8)$ & $2.7(1.9-3.9)$ & $2.8(2.1-3.8)$ \\
\hline \multirow[t]{2}{*}{ Creatinine (g/24 hours) } & $1.33(0.71)$ & $1.72(0.87)$ & $1.13(0.52) \ddagger$ \\
\hline & $1.18(0.86-1.63)$ & $1.61(1.16-2.12)$ & $1.02(0.81-1.36)$ \\
\hline \multirow[t]{2}{*}{ Salt intake (g/day) } & $9.0(4.9)$ & $9.6(5.5)$ & $8.7(4.6)^{\star}$ \\
\hline & $8.1(5.3-11.7)$ & $8.5(5.4-12.8)$ & $7.9(5.2-11.2)$ \\
\hline \multirow[t]{2}{*}{ Potassium intake (g/day) } & $2.36(1.46)$ & $2.53(1.45)$ & $2.27(1.46)^{\star}$ \\
\hline & $2.08(1.41-2.91)$ & $2.28(1.52-3.28)$ & $2.00(1.35-2.76)$ \\
\hline Salt $<5$ g/day N (\%) & $124(21.8)$ & $40(20.7)$ & $84(22.3)$ \\
\hline Potassium >90 mmol/day N (\%) & $52(9.1)$ & $24(12.4)$ & $28(7.4) \dagger$ \\
\hline
\end{tabular}

Results are mean (SD) and median (25th-75th percentile) or N (\%).

${ }^{*} \mathrm{p}<0.05$.

$\mathrm{tp}=0.008$.

$\neq \mathrm{p}<0.001$.

Table 4 Knowledge, attitudes and behaviours towards salt consumption

\begin{tabular}{|c|c|c|c|}
\hline Question & All $(n=569)$ & Men $(n=193)$ & Women $(n=376)$ \\
\hline \multicolumn{4}{|c|}{ How often do you add salt or salty sauces to your food? } \\
\hline Often/always & $28.1 \%$ & $22.8 \%$ & $30.8 \% *$ \\
\hline Sometimes & $21.3 \%$ & $17.1 \%$ & $23.4 \%$ \\
\hline Rarely/never & $50.6 \%$ & $60.1 \%$ & $45.8 \%$ \\
\hline \multicolumn{4}{|c|}{ How often is salt, salty seasoning or salty sauces added in cooking or preparing food at home? $\ddagger$} \\
\hline Often/always & $47.0 \%$ & $44.8 \%$ & $48.1 \% \dagger$ \\
\hline Sometimes & $16.5 \%$ & $12.5 \%$ & $18.6 \%$ \\
\hline Rarely/never & $36.5 \%$ & $42.7 \%$ & $33.3 \%$ \\
\hline \multicolumn{4}{|c|}{ How often do you eat processed food? $\ddagger$} \\
\hline Often/always & $22.3 \%$ & $22.8 \%$ & $22.1 \%$ \\
\hline Sometimes & $38.3 \%$ & $35.8 \%$ & $39.5 \%$ \\
\hline Rarely/never & $39.4 \%$ & $41.4 \%$ & $38.4 \%$ \\
\hline \multicolumn{4}{|c|}{ How much salt or salty sauces do you think you consume? $\ddagger$} \\
\hline Too much/far too much & $6.9 \%$ & $7.8 \%$ & $6.4 \%$ \\
\hline Just the right amount & $66.8 \%$ & $61.3 \%$ & $69.7 \%$ \\
\hline Too little/far too little & $26.3 \%$ & $30.9 \%$ & $23.9 \%$ \\
\hline \multicolumn{4}{|c|}{ Do you think that too much salt or salty sauces could cause a serious health problem? $¥$} \\
\hline Yes & $89.1 \%$ & $90.1 \%$ & $88.6 \%$ \\
\hline
\end{tabular}

${ }^{\star}$ Results are percentages $\mathrm{p}=0.005$.

$\mathrm{tp}=0.04$ when compared with men.

‡Reduced numbers due to missing values. 


\begin{tabular}{|c|c|c|c|}
\hline Question & $\begin{array}{l}\text { All } \\
(n=569)\end{array}$ & $\begin{array}{l}\text { Men } \\
(n=193)\end{array}$ & $\begin{array}{l}\text { Women } \\
(n=376)\end{array}$ \\
\hline \multicolumn{4}{|c|}{ In a typical week, on how many days do you eat fruit?§ } \\
\hline$<5$ & $32.0 \%$ & $40.4 \%$ & $27.7 \% \dagger$ \\
\hline$\geq 5$ & $68.0 \%$ & $59.6 \%$ & $72.3 \%$ \\
\hline
\end{tabular}

How many servings of fruit do you eat on one of those days?§

\begin{tabular}{|c|c|c|c|}
\hline$<3$ & $45.5 \%$ & $41.8 \%$ & $47.2 \%$ \\
\hline$\geq 3$ & $54.5 \%$ & $58.2 \%$ & $52.8 \%$ \\
\hline \multicolumn{4}{|c|}{$\begin{array}{l}\text { In a typical week, on how many days do you eat } \\
\text { vegetables?§ }\end{array}$} \\
\hline$<5$ & $24.1 \%$ & $24.9 \%$ & $23.7 \%$ \\
\hline$\geq 5$ & $75.9 \%$ & $75.1 \%$ & $76.3 \%$ \\
\hline
\end{tabular}

How many servings of vegetables do you eat on one of those days?§

$\begin{array}{llll}<3 & 59.9 \% & 65.9 \% & 56.9 \% \ddagger \\ \geq 3 & 40.1 \% & 34.1 \% & 43.1 \%\end{array}$

What type of oil or fat is most often used for meal preparation in your household?§

\begin{tabular}{|c|c|c|c|}
\hline Vegetable oil & $90.8 \%$ & $91.1 \%$ & $90.7 \%$ \\
\hline $\begin{array}{l}\text { Other (lard, suet, butter, } \\
\text { ghee) }\end{array}$ & $9.0 \%$ & $8.9 \%$ & $9.0 \%$ \\
\hline None used & $0.2 \%$ & 0 & $0.3 \%$ \\
\hline \multicolumn{4}{|c|}{$\begin{array}{l}\text { On average, how many meals per week do you eat that were } \\
\text { not prepared at home?§ }\end{array}$} \\
\hline 0 & $45.8 \%$ & $32.1 \%$ & $52.8 \%$ * \\
\hline$\geq 1$ & $54.2 \%$ & $67.9 \%$ & $47.2 \%$ \\
\hline
\end{tabular}

${ }^{*}$ Results are percentages $\mathrm{p}<0.0001$.

$\mathrm{tp}=0.002$.

$\ddagger \mathrm{p}=0.04$ versus men

§Reduced numbers due to missing values.

they added salt or salty sauces always or often to food. The percentage of women who added salt or salty sauces always or often to their meal was significantly higher than that of men $(30.8 \%$ vs $22.8 \%$; $\mathrm{p}=0.005)$. A total of $47.0 \%$ of respondents reported that they always or often added salt, salty seasonings or sauces when cooking or preparing food at home, women more than men $(48.1 \%$ vs $44.8 \% ; \mathrm{p}=0.04)$. More than 1 in $5(22.3 \%)$ mentioned that they consumed processed foods high in salt always or often. Very few $(6.9 \%)$, however, felt they consumed too much salt or salty sauces, although $89.1 \%$ knew that consuming too much salt could cause serious health problems. We also asked participants about dietary attitudes about the consumption of fruit and vegetables, oil or fats (table 5). Interestingly, $68.0 \%$ consumed fruit at least 5 days a week and $54.5 \%$ at least three servings on these days. Men appeared to report more fruit consumption than women did ( $40.4 \%$ vs $27.7 \%$; $\mathrm{p}=0.002)$. Vegetables were also consumed frequently $(75.9 \%$ at least 5 days a week), with $40.1 \%$ having at least three servings on one of those days (women more frequently than men). The majority $(90.8 \%)$ used vegetable oil for meal preparation in the household and more than half $(54.2 \%)$ consumed food prepared outside home at least once a week. Men were more likely than women to do so $(67.9 \%$ vs $47.2 \%$; $\mathrm{p}<0.001)$.

\section{DISCUSSION}

This is the first nationally representative population-based survey carried out in the Sultanate of Oman assessing dietary sodium and potassium consumption in adult Omani men and women, using the gold standard measure of 24-hour urinary sodium and potassium excretions as a biomarker of intake. The results show that salt consumption is higher and potassium consumption is lower than recommended by the WHO, ${ }^{1423}$ both in men and women. Average population salt consumption was $9.0 \mathrm{~g} /$ day, almost double the WHO recommended maximum population target of $5 \mathrm{~g}$ /day. ${ }^{14}$ Less than one in four participants met these targets. Salt consumption varied across governorates, being the lowest in South Sharqiah $(5.3 \mathrm{~g} /$ day $)$ and the highest in Al-Dhahirah $(14.8 \mathrm{~g} /$ day $)$. Average population excretion of potassium was $53 \mathrm{mmol} /$ day (equivalent to about $2.36 \mathrm{~g} /$ day), lower than the WHO recommended maximum population target of $>90 \mathrm{mmol} /$ day, equivalent to approximately $3.90 \mathrm{~g} /$ day (assuming urinary potassium being $85 \%$ of the intake). ${ }^{23}$ Potassium consumption also varied across governorates, being the lowest in Al-Wasta (1.41 g/day) and the highest in North Sharqiah $(4.25 \mathrm{~g} /$ day). The urinary sodium-topotassium ratio averaged 3.3, with no difference between men and women. Findings from the International Collaborative Study on Salt (INTERSALT) study showed that a difference in sodium-to-potassium ratio from 3.1 to 1.0 was associated with a $3.36 \mathrm{~mm} \mathrm{Hg}$ difference in population systolic BP. ${ }^{32} 33$ The Trial Of Hypertension Prevention (TOHP) study reported a direct association between the urinary sodium-to-potassium ratio and CVD. ${ }^{10}{ }^{34} 35$ Moreover, a unit difference in the ratio would be associated with a $13 \%$ reduction in total mortality. ${ }^{35}$ Measuring the ratio is obviously important, although no evidence-based global guidelines have determined population targets, as yet.

Our questionnaire revealed that half of the population seen often used sauces and condiments (invariably containing high concentrations of salt) but only $10 \%$ believed this was too much. A quarter of the surveyed population added salt to food regularly, one in five ate processed food often and more than half of the population ate out at least once a week, with men more likely than women. These results, in addition to those obtained in previous surveys on unhealthy dietary habits, support the National Health Vision set by the Sultanate of Oman to reduce the burden of CVD. ${ }^{36}$ This document sets the health visions for the country in 40 years. The comprehensive analyses of many factors affecting the population health and the healthcare system indicate that NCDs, 
in the context of increased life expectancy and population ageing, pose a significant threat to the health of the Omani people and it identifies the need to be able to respond to this challenge. Population salt reduction is one of the priorities.

\section{Comparison with countries of the Gulf Co-operation Council and of the Arab Peninsula}

In the Gulf Co-operation Council (GCC) countries, populations lead a sedentary lifestyle, both hypertension and obesity are common ${ }^{17}$ and they are major contributors to NCDs. ${ }^{37}$ The estimated total mortality in GCC countries attributable to NCDs varies from $65 \%$ to $78 \%$, with the highest estimates in Bahrain and Saudi Arabia and the lowest in Oman and Qatar, respectively. ${ }^{37}$ Salt intake is deemed high in most countries of the EMRO Region, although there are only a few studies that directly measured population levels, with inconsistent results due to methodological inadequacies. ${ }^{17} 18$ The Global Burden of Disease (GBD) estimates of average salt consumption using a Bayesian model suggest that salt consumption in GCC countries may vary from $8.0 \mathrm{~g}$ /day in Saudi Arabia to $13.5 \mathrm{~g} /$ day in Bahrain. ${ }^{38}$ Estimates of salt intake in neighbouring countries would also range between $7.8 \mathrm{~g} /$ day in Lebanon and $10.3 \mathrm{~g}$ /day in Jordan. ${ }^{38}$ The present study is one of the few nationally representative surveys in GCC countries using the gold standard method of assessment of dietary salt intake. Its results suggest an intake close to that estimated by the GBD. In addition to the GBD, however, our study also provides, for the first time, direct measures of average population potassium consumption also targeted by WHO recommendations for cardiovascular prevention. ${ }^{20} 23$

Many countries of the EMRO Region of WHO are developing and/or implementing national initiatives to decrease population salt intake. ${ }^{18}$ National initiatives include the establishment of national multisectoral committees, the engagement of the government through regulatory measures and legislation (Bahrain, Iran, Jordan, Oman, Qatar), the specification of the food categories prioritised for action such as bread (Kuwait, Qatar) and canned foods (Iran), the development of national benchmarks and targets (Bahrain, Iran, Oman), dietary guidelines (Afghanistan, Lebanon, Oman, Saudi Arabia), media awareness campaigns (Lebanon, United Arab Emirates), salt labelling, collaborative actions involving the food industry and/or restaurants and food caterers (Kuwait, Qatar, United Arab Emirates) and the monitoring and evaluation of sodium intakes and salt content of foods (Iran, Lebanon, Oman, Qatar).

\section{Comparisons with studies in other countries}

National salt and potassium consumption surveys have been carried out in almost all regions of the world, especially in response to the recommendations from the WHO that identified population salt reduction as one of the most cost-effective and feasible approaches to prevent NCDs. ${ }^{23}$ Globally, there is a high variation in the readiness of countries to adopt and implement the different aspects of the overall strategy, with low-income and middleincome countries still lagging behind. ${ }^{39} 40$ Nevertheless, where surveys have been carried out to establish the size of the problem, average levels of salt intake have been very high in countries of Eastern Europe $(10.8 \mathrm{~g} /$ day in Moldova and $11.6 \mathrm{~g} /$ day in Montenegro with potassium about $30 \%$ lower than recommended and sodium-topotassium ratios of 3.0 and 2.4, respectively), ${ }^{41} 42$ Central Asia (17.2 and $18.8 \mathrm{~g} /$ day in two sites of Kazakhstan) ${ }^{43}$ China (twofold North-South gradient from 15.6 to $8.4 \mathrm{~g} /$ day and potassium about $60 \%$ lower than recommended) ${ }^{44}$ and Australasia (about $9.0 \mathrm{~g} /$ day weighted means in Australia and $11.7 \mathrm{~g}$ /day in the Fiji Islands), ${ }^{45} 46$ indicating urgent need for population interventions. The same studies have invariably indicated lower than recommended potassium excretion and high sodium-topotassium ratio. In this respect, the average intake of sodium in Oman seems reassuring, as the achievement of the set targets appears more feasible that in other countries where intake currently still exceeds $10 \mathrm{~g}$ /day. However, potassium consumption is nearly half of what is recommended, ${ }^{23}$ resulting in a high sodium-to-potassium ratio.

\section{Strengths and limitations}

Our study has several strengths. First, it is a populationbased survey across the whole country. Second, it included all adults. Third, it included both men and women. These study characteristics would allow with greater confidence the extrapolation of results to the whole country population, rather than those conducted in selected groups including patients, ${ }^{47}$ young female university students ${ }^{48}$ or children. ${ }^{49}$ Fourth, it used the current preferred methodology for estimating salt consumption. Fifth, we applied a rigorous quality control protocol to ensure completeness of urine collections and to minimise both under and overestimations. Current recommendations suggest the use of single complete 24-hour urine samples, collected from a representative population sample to assess the population's current 24-hour dietary sodium ingestion. ${ }^{50}$ The role of single-spot or short duration timed urine collections in assessing population average sodium intake requires more research. Single or multiple spot or short duration timed urine collections are, on the other hand, not recommended for assessing an individual's sodium intake especially in relationship to health outcomes. ${ }^{50}$ Twenty-four-hour diet recall and diet records inaccurately measure dietary sodium intake in individuals compared with the gold standard 24-hour urinary excretion. ${ }^{51}$ Furthermore, there is poor agreement between estimates of sodium intake from food-frequency questionnaires and 24-hour urine samples. ${ }^{52}$ Sixth, it has measured directly the amount of potassium consumption, additional nutrient targeted for cardiovascular prevention. ${ }^{20} 23$ Seventh, we standardised fieldwork and used standardised laboratory methodologies across the country. Eighth, all laboratories underwent joint quality control. ${ }^{25}$ 
There are limitations too. First, we included only $57 \%$ of the urine samples originally collected from willing individuals. This was due to the stringent quality control that has led to the exclusion of incomplete or erroneous collections. ${ }^{24}$ This could have introduced a self-selection bias. The comparison of the baseline characteristics of the studies sample versus the excluded group suggests that the two groups were comparable for general characteristics, with the exception of the latter being 2 years younger and having a $1.8 \mathrm{~mm} \mathrm{Hg}$ lower diastolic BP. Second, we assessed urinary sodium and potassium excretions only once. While we cannot characterise an individual's intake in such a way, ${ }^{50}$ there is less likelihood of a bias of group estimates. Third, although we requested participants not to change their diet prior to urine collection, it would be difficult to rule out entirely any bias during collection. Fourth, although we administered a questionnaire to derive KABs towards the use of salt, we were unable to establish the relative contribution of discretionary sources of salt and the most common foods contributing to salt as well as potassium consumption.

\section{Potential impact}

The population in the Sultanate of Oman is of just over 5 million (Ministry of Health Annual Health Report, 2018 estimates), of which about 2.3 million are Omani nationals ${ }^{4}$ (surveyed in the present study). Approximately $51 \%$ are 25 years or older. To meet a $30 \%$ reduction in population salt consumption set by WHO by 2025 , the Sultanate of Oman should aim at a $2.7 \mathrm{~g} /$ day salt reduction nationally. This reduction would avert $8.1 \%$ CVD deaths per year and more non-fatal events and disabilities. ${ }^{2}$ Additional benefits would be achieved if we increased at the same time population potassium intake towards WHO set targets, leading to a significant reduction in the sodiumto-potassium ratio in the diet. This could be achieved not only by increasing consumption of plant-based foods but also by enriching the diet with potassium-rich salt substitution in food manufacturing and processing or by using potassium-reach salts instead of sodium chloride, where sodium intake is predominantly originating from discretionary sources. Potassium-rich salts lower BP effectively ${ }^{53}$ and the potential risk associated with potassium supplementation used at a population level ${ }^{54}$ would be offset by a net reduction in CVD deaths. ${ }^{55}$

\section{Policy implications}

The Sultanate of Oman has embraced among its health priorities the prevention and control of NCDs and improvement in nutrition ${ }^{4}$ in line with the strategic directions of WHO endorsed by the EMRO in 2012 and $2013^{18}$. Since then several countries have conducted dietary studies in an attempt to assess the population's salt and potassium intake. ${ }^{18}$ Studies in the area have also attempted to identify the major dietary contributors to sodium intake. Studies are still limited and there are large variations in dietary habits in the region due to cultural, ethnic, religious and social heterogeneity. The most common source of salt consumption across the region is bread, ${ }^{1856}$ in all its different forms, with other sources being more relevant in different countries. In Lebanon ${ }^{57}$ and Bahrain, ${ }^{58}$ dairy products are common sources, while in Morocco, ${ }^{59}$ major contributors to salt consumption include cereal-based products, spices and condiments and milk products. These indications, together with the awareness and behaviours measured, suggest that to reduce population salt consumption in the Sultanate of Oman, the following initiatives should be taken: (a) improving salt-related knowledge through health promotion campaigns, (b) measuring major sources of salt consumption, (c) establishing collaborations with local authorities to reduce the amount of salt used in traditional bread making and locally produced condiments, (d) adopting a labelling strategy for imported foods with high salt content. In addition, the Ministry of Health should develop strategies and methodologies to measure the indicators of population salt consumption. ${ }^{60}$

\section{CONCLUSIONS}

This study demonstrates that salt consumption in the Sultanate of Oman is high and should be reduced through a public health action aiming at the entire population. Likewise, potassium consumption is particularly low. The KABs survey indicates areas of limited awareness. Education of the dangers of high salt consumption and where salt is hidden, of the benefits of increasing potassium through fruit, vegetables, nuts and legumes, alongside accurate labelling and marketing of food, surveillance to measure and monitor salt use and reformulating bread are all important elements of an effective national salt reduction programme. ${ }^{181961}$

\section{Author affiliations}

${ }^{1}$ Centre of Studies \& Research, Ministry of Health, Muscat, Oman

${ }^{2}$ The Research Council, Seeb, Oman

${ }^{3}$ WHO Collaborating Centre for Nutrition, University of Warwick, Coventry, UK ${ }^{4}$ Department of Clinical Medicine and Surgery, "Federico II" University of Naples Medical School, Naples, Italy

${ }^{5}$ Division of Health Sciences, Warwick Medical School, University of Warwick, Coventry, UK

${ }^{6}$ Division of Medicine, University Hospitals Coventry \& Warwickshire NHS Trust, Coventry, UK

Acknowledgements We carried out the present analysis under the terms of reference of the WHO Collaborating Centre for Nutrition at the University of Warwick. The authors would like to express gratitude to the EMRO WHO Regional Office (Dr Ayoub Al-Jawaldeh) and the WHO Country Office of Oman (Dr Ruth Mabry) for facilitating the study, the Department of Food Science and Human Nutrition of Sultan Qaboos University (Dr Lyutha Al-Subhi) and other members of the Ministry of Health (Dr Amel Ibrahim, Dr Ruqaya Balushi and Dr Salima) for their helpful discussions in the preparation of the protocol. Special thanks go to the team of the Ministry of Health of the Sultanate of Oman involved in the preparation of the survey and data collection. Finally, we wish to express our gratitude to His Excellency the Under secretary for Health Affairs of the Sultanate of Oman, Dr Mohammed bin Saif Al Hosni, and his Advisor, Dr Mahmood Shaban, for their advice, endorsements and support at a national level.

Contributors FPC developed the study design and protocol, contributed to the analysis and drafted the manuscript, AA-M trained local teams, coordinated quality control and data collection. MM and LD carried out quality control and statistical 
analysis. AA-M, SKJ, WNA-S, ADP, HA-K, ZA-B, Jl, AA-H coordinated the study, carried out the fieldwork and liaised with the local laboratory. MM helped with the drawing of the stratified random sample from the sampling frame. All authors contributed to the interpretation of the findings and they contributed significantly to the final version of the manuscript. FPC is the guarantor.

Funding The Ministry of Health of the Sultanate of Oman and the EMRO Regional Office of the World Health Organization supported the study.

Competing interests AA-M, SKJ, MM, WNA-S, ADP, HA-K, ZA-B, JI, AA-H are all staff of the Ministry of Health of the Sultanate of Oman. FPC is a technical advisor to the World Health Organization, unpaid member of Action on Salt and WASH. LD was a technical advisor to the World Health Organization and is a member of the Scientific Committee of the Italian Society of Human Nutrition.

Patient consent for publication Not required.

Ethics approval We obtained ethical approval for the survey from the Research and Ethics Review and Approval Committee (RERAC) of the Ministry of Health of the Sultanate of Oman and participants provided written informed consent to take part

Provenance and peer review Not commissioned; externally peer reviewed.

Data availability statement Data are available upon reasonable request. No individual participant data will be available. Study protocol available in Supplementary Material. Any other data sharing proposal must be submitted in writing to the Ministry of Health of the Sultanate of Oman.

Supplemental material This content has been supplied by the author(s). It has not been vetted by BMJ Publishing Group Limited (BMJ) and may not have been peer-reviewed. Any opinions or recommendations discussed are solely those of the author(s) and are not endorsed by BMJ. BMJ disclaims all liability and responsibility arising from any reliance placed on the content. Where the content includes any translated material, BMJ does not warrant the accuracy and reliability of the translations (including but not limited to local regulations, clinical guidelines, terminology, drug names and drug dosages), and is not responsible for any error and/or omissions arising from translation and adaptation or otherwise.

Open access This is an open access article distributed in accordance with the Creative Commons Attribution 4.0 Unported (CC BY 4.0) license, which permits others to copy, redistribute, remix, transform and build upon this work for any purpose, provided the original work is properly cited, a link to the licence is given, and indication of whether changes were made. See: https://creativecommons.org/ licenses/by/4.0/.

ORCID iD

Francesco P Cappuccio http://orcid.org/0000-0002-7842-5493

\section{REFERENCES}

1 GBD 2015 Mortality and Causes of Death Collaborators. Global, regional, and national life expectancy, all-cause mortality, and causespecific mortality for 249 causes of death, 1980-2015: a systematic analysis for the global burden of disease study 2015. Lancet 2016;388:1459-544.

2 World Health Organization. Global action plan for the prevention and control of NCDS 2013-2020. Geneva, Switzerland: World Health Organization, 2013: 1-103.

3 World Health Organization. Tackling NCDs: "Best buys" and other recommended interventions for the prevention and control of noncommunicable diseases, 2017. Available: http://www.who.int/ ncds/management/best-buys/en/

4 World Health Organization. Oman health profile 2018. Cairo, Egypt: World Health Organization. Regional -Office for the Eastern Mediterranean, 2016: 1-37.

5 Al-Mawali A. Non-Communicable diseases: shining a light on cardiovascular disease, Oman's biggest killer. Oman Med J 2015;30:227-8

6 Al Riyami A, Elaty MAA, Morsi M, et al. Oman world health survey: part 1 - methodology, sociodemographic profile and epidemiology of non-communicable diseases in Oman. Oman Med J 2012;27:425-43.

7 Aburto NJ, Ziolkovska A, Hooper L, et al. Effect of lower sodium intake on health: systematic review and meta-analysis. Br Med J 2013;346:f1326.

8 He FJ, Li J, Macgregor GA. Effect of longer term modest salt reduction on blood pressure: Cochrane systematic review and metaanalysis of randomised trials. Br Med J 2013;346:f1325.

9 Strazzullo P, D'Elia L, Kandala N-B, et al. Salt intake, stroke, and cardiovascular disease: meta-analysis of prospective studies. $\mathrm{Br}$ Med J 2009;339:b4567.
10 Cook NR, Cutler JA, Obarzanek E, et al. Long term effects of dietary sodium reduction on cardiovascular disease outcomes: observational follow-up of the trials of hypertension prevention (TOHP). Br Med J 2007;334:885-8.

11 Cappuccio FP. Cardiovascular and other effects of salt consumption. Kidney Int Suppl 2013;3:312-5

12 D'Elia L, Rossi G, Schiano di Cola M, et al. Meta-analysis of the effect of dietary sodium restriction with or without concomitant reninangiotensin-aldosterone System-Inhibiting treatment on albuminuria. Clin J Am Soc Nephrol 2015;10:1542-52.

13 D'Elia L, Galletti F, La Fata E, et al. Effect of dietary sodium restriction on arterial stiffness: systematic review and meta-analysis of the randomized controlled trials. J Hypertens 2018;36:734-43.

14 World Health Organization. Guideline: sodium intake for adults and children. Geneva, Switzerland: World Health Organization, 2012.

15 Brown IJ, Tzoulaki I, Candeias V, et al. Salt intakes around the world: implications for public health. Int J Epidemiol 2009;38:791-813.

16 Cappuccio FP, Capewell S. Fact issues, and controversies in salt reduction for the prevention of cardiovascular disease. Funct Food Rev 2015;7:41-61.

17 Alhamad N, Almalt E, Alamir N, et al. An overview of salt intake reduction efforts in the Gulf Cooperation Council countries. Cardiovasc Diagn Ther 2015;5:172-7.

18 Al Jawaldeh A, Rafii B, Nasreddine L. Salt intake reduction strategies in the eastern Mediterranean region. East Mediterr Health $J$ 2018;24:1172-80.

19 Cappuccio FP, Capewell S, Lincoln P, et al. Policy options to reduce population salt intake. Br Med J 2011;343:402-5.

20 Aburto NJ, Hanson S, Gutierrez H, et al. Effect of increased potassium intake on cardiovascular risk factors and disease: systematic review and meta-analyses. Br Med J 2013;346:f1378.

21 D'Elia L, Barba G, Cappuccio FP, et al. Potassium intake, stroke, and cardiovascular disease a meta-analysis of prospective studies. J Am Coll Cardiol 2011;57:1210-9.

22 D'Elia L, lannotta C, Sabino $\mathrm{P}$, et al. Potassium-rich diet and risk of stroke: updated meta-analysis. Nutr Metab Cardiovasc Dis 2014;24:585-7

23 World Health Organization. Guideline: potassium intake for adults and children. World Health Organization: Geneva, Switzerland, 2012: 1-52.

24 World Health Organization. How to obtain measures of populationlevel sodium intake in 24-hour urine samples. Cairo, Egypt: World Health Organization, Regional Office of the Eastern Mediterranean 2018: 1-51.

25 World Medical Association. Declaration of Helsinki. Recommendations guiding doctors in clinical research. Bull World Health Org 2008;86:650-1.

26 World Health Organization. The WHO stepwise approach to chronic disease risk factor surveillance (STEPS). World Health Organization, Geneva, Switzerland, 2014. Available: https://www.who.int/ncds/ surveillance/steps/STEPS_Instrument_v2.1.pdf

27 Mancia G, Fagard R, Narkiewicz K, et al. ESH/ESC guidelines for the management of arterial hypertension: the task force for the management of arterial hypertension of the European Society of Hypertension (ESH) and of the European Society of Cardiology (ESC). J Hypertens 2013;31:1281-357.

28 Oesch U, Ammann D, Simon W. Ion-Selective membrane electrodes for clinical use. Clin Chem 1986;32:1448-59.

29 Junge W, Wilke B, Halabi A, et al. Determination of reference intervals for serum creatinine, creatinine excretion and creatinine clearance with an enzymatic and a modified Jaffé method. Clin Chim Acta 2004:344:137-48.

30 Lucko AM, Doktorchik C, Woodward M, et al. Percentage of ingested sodium excreted in 24-hour urine collections: a systematic review and meta-analysis. J Clin. Hypertens 2018;20:1220-9.

31 Stamler J, Elliott P, Chan Q. For the INTERMAP Research Group INTERMAP appendix tables. J Hum Hypertens 2003;17:665-758.

32 Rose G, Stamler J, Stamler R, et al. INTERSALT: an international study of electrolyte excretion and blood pressure. results for $24 \mathrm{~h}$ urinary sodium and potassium excretion. Br Med $\mathrm{J}$ 1988;297:319-32.

33 Stamler J, Rose G, Stamler R, et al. INTERSALT study findings. public health and medical care implications. Hypertension 1989;14:570-7.

34 Cook NR, Obarzanek E, Cutler JA, et al. Joint effects of sodium and potassium intake on subsequent cardiovascular disease: the trials of hypertension prevention follow-up study. Arch Intern Med 2009;169:32-4.

35 Cook NR, Appel LJ, Whelton PK. Sodium intake and all-cause mortality over 20 years in the trials of hypertension prevention. J Am Coll Cardiol 2016;68:1609-17. 
36 Ministry of Health. Health vision 2050. The main document. Undersecretariat for planning Affairs, Ministry of health, Sultanate of Oman, 2014: 1-212. http://www.nationalplanningcycles.org/sites/ default/files/planning_cycle_repository/oman/health_vision_2050_ oman.pdf

37 World Health Organization. Noncommunicable diseases country health profiles, 2019. Available: http://www.emro.who.int/entity/ statistics/country-health-profiles.htm

38 Powles J, Fahimi S, Micha R, et al. Global, regional and national sodium intakes in 1990 and 2010: a systematic analysis of $24 \mathrm{H}$ urinary sodium excretion and dietary surveys worldwide. BMJ Open 2013;3:e003733.

39 Rodriguez-Fernandez R, Siopa M, Simpson SJ, et al. Current salt reduction policies across gradients of inequality-adjusted human development in the WHO European region: minding the gaps. Public Health Nutr 2014;17:1894-904.

40 Trieu K, Neal B, Hawkes C, et al. Salt reduction initiatives around the world - a systematic review of progress towards the global target. PLoS One 2015;10:e0130247.

41 D'Elia L, Brajović M, Klisic A, et al. Sodium and potassium intake, knowledge attitudes and behaviour towards salt consumption amongst adults in Podgorica, Montenegro. Nutrients 2019;11:160.

42 D'Elia L, Obreja G, Ciobanu A, et al. Sodium, potassium and iodine intake in a national adult population sample of the Republic of Moldova. Nutrients 2019;11:2896.

43 Trieu K, Ospanova F, Sharmanov T, et al. Mean urinary salt excretion in two Kazakhstan regions - one of the highest in the world. $J$ Hypertens 2018;36:e334.

44 Tan M, He FJ, Wang C, et al. Twenty-four-hour urinary sodium and potassium excretion in China: a systematic review and metaanalysis. J Am Heart Assoc 2019;8:e012923.

45 Land M-A, Webster J, Christoforou A, et al. Salt intake assessed by $24 \mathrm{H}$ urinary sodium excretion in a random and opportunistic sample in Australia. BMJ Open 2014;4:e003720.

46 Pillay A, Trieu K, Santos JA, et al. Assessment of a salt reduction intervention on adult population salt intake in Fiji. Nutrients 2017:9:1350.

47 Alkhunaizi AM, Al Jishi HA, Al Sadah ZA. Salt intake in eastern Saudi Arabia. East Mediterr Health J 2013;19:915-8.

48 Tayel DI, Amine AK, Elzawi AK. Dietary intake of nutrients related to bone health among Alexandria university female students, Egypt. Food and Public Health 2013;3:329-35.
49 Kelishadi R, Gheisari A, Zare N, et al. Salt intake and the association with blood pressure in young Iranian children: first report from the middle East and North Africa. Int J Prev Med 2013;4:475-83.

50 Campbell NRC, He FJ, Tan M, et al. The international consortium for quality research on dietary sodium/salt (TRUE) position statement on the use of 24-hour, spot, and short duration ( $<24$ hours) timed urine collections to assess dietary sodium intake. J Clin Hypertens 2019;21:700-9.

51 McLean RM, Farmer VL, Nettleton A, et al. Twenty-four-hour diet recall and diet records compared with 24-hour urinary excretion to predict an individual's sodium consumption: a systematic review. J Clin Hypertens 2018;20:1360-76.

52 McLean RM, Farmer VL, Nettleton A, et al. Assessment of dietary sodium intake using a food frequency questionnaire and 24-hour urinary sodium excretion: a systematic literature review. J Clin Hypertens 2017;19:1214-30.

53 Peng Y-G, Li W, Wen X-X, et al. Effects of salt substitutes on blood pressure: a meta-analysis of randomized controlled trials. Am J Clin Nutr 2014;100:1448-54.

54 Marklund M, Singh G, Greer R, et al. Estimated population wide benefits and risks in China of lowering sodium through potassium enriched salt substitution: modelling study. Br Med J 2020;369:m824.

55 Cappuccio FP, Buchanan LA, Ji C, et al. Systematic review and meta-analysis of randomised controlled trials on the effects of potassium supplements on serum potassium and creatinine. BMJ Open 2016;6:e011716.

56 Almedawar MM, Nasreddine L, Olabi A, et al. Sodium intake reduction efforts in Lebanon. Cardiovasc Diagn Ther 2015;5:178-85.

57 Nasreddine L, Akl C, Al-Shaar L, et al. Consumer knowledge, attitudes and salt-related behavior in the Middle-East: the case of Lebanon. Nutrients 2014;6:5079-102.

58 Ministry of Health (Bahrain). National nutrition survey for adult Bahrainis aged 19 years and above 2002

59 Derouiche A, Jafri A, El Kardi Y. Assessment of salt, fat content, and intake in largely consumed foods in Morocco. Report of a pilot study, 2014: 1-92.

60 Bonita R, Magnusson R, Bovet P, et al. Country actions to meet un commitments on non-communicable diseases: a stepwise approach. Lancet 2013;381:575-84.

61 Farrand C, FJ H, MacGregor GA. Reducing population salt intake in the eastern Mediterranean region - time for urgent action. Eastern Med. Health J 2014;20:761-4. 